\title{
Marketing de relacionamento: estudo das estratégias que visam a satisfação dos clientes de uma fábrica de rações
}

\author{
Alana Laís Fahl \\ Universidade Regional Do Noroeste Do Estado Do Rio Grande Do Sul - Unijuí \\ (alana_fahl.pbi@hotmail.com) \\ Adriane Fabricio \\ Universidade Federal De Santa Maria - Ufsm \\ Universidade Regional Do Noroeste Do Estado Do Rio Grande Do Sul - Unijuí \\ (adriane.fabricio@unijui.edu.br) \\ Liane Beatriz Rotili \\ Universidade Regional Do Noroeste Do Estado Do Rio Grande Do Sul - Unijuí \\ (Liane.Rotili@Hotmail.Com) \\ Daniel Knebel Baggio, \\ Universidade Regional Do Noroeste Do Estado Do Rio Grande Do Sul - Unijuí \\ (baggiod@unijui.edu.br) \\ Linéia Carneiro \\ Universidade Regional Do Noroeste Do Estado Do Rio Grande Do Sul - Unijuí \\ (lineiacarneiro@yahoo.com.br)
}

\begin{abstract}
Resumo: O termo marketing de relacionamento é utilizado para todos os serviços de uma organização que visam atrair, manter e conquistar o cliente, transformando clientes eventuais em clientes fiéis (BERRY,1983; GRÖNROOS, 1994; MORGAN; HUNT, 1994; ROBICHEAUX; COLEMAN,1995; KOTLER, 1998; LOPES; FREITAS; MOTA, 2015). Diante desse contexto, o objetivo deste estudo é analisar as estratégias utilizadas para satisfazer os clientes de uma fábrica de ração da região noroeste do estado do Rio Grande do Sul, a partir da avaliação da percepção dos clientes e do público interno da empresa. Metodologicamente, este estudo é uma pesquisa aplicada, descritiva, quantitativa. Os resultados obtidos demostraram que os clientes estão, em geral, satisfeitos com as estratégias da empresa no que tange à qualidade $(77 \%)$, à apresentação e linha $(75 \%)$ e ao preço (67\%) dos produtos, sendo que a qualidade dos produtos é citada pela maioria dos clientes como fator de conquista dos mesmos $(28 \%)$ e como fator de recompra $(31 \%)$, dados corroborados pelo público interno.
\end{abstract}

Palavras-chave: Marketing de relacionamento; Satisfação do cliente; Estratégias de marketing.

\section{Relationship marketing: study of strategies for the satisfaction of customers of an animal feed factory}

Abstract: The term "relationship marketing" is used for all the services of an organization aimed to attract, maintain and win the customer, turning potential customers into loyal customers (BERRY,1983; GRÖNROOS, 1994; MORGAN; HUNT, 1994; ROBICHEAUX; COLEMAN,1995; KOTLER, 1998; LOPES; FREITAS; MOTA, 2015). In this context, this study aimed to analyze the strategies used to satisfy customers of a northwest feed mill of Rio Grande do Sul, through an evaluation of the perception of customers and internal stakeholders of the company. Methodologically 
this study is an applied research, descriptive and quantitative. The results showed that customers are generally satisfied with the company's strategies with regard to quality $(77 \%)$, presentation and online $(75 \%)$ and price $(67 \%)$ of product, and the product quality is cited by most customers as achievement factor of them $(28 \%)$ and as repurchase factor $(31 \%)$. All these data were corroborated by similar data obtained with the internal public.

Keywords: Marketing relationship; Customer satisfaction; Marketing strategies.

\section{INTRODUÇÃO}

Até o início do século $\mathrm{XX}$, as empresas detinham total poder sobre o mercado, preocupavam-se apenas em escoar seus produtos e serviços para que pudessem obter sucesso em seus negócios, determinavam suas próprias regras e o cliente era visto apenas como uma fonte de lucros. No entanto, o cenário econômico atual possui uma nova configuração, em que fatores como a globalização, a tecnologia e a entrada de novas empresas permitem, ao cliente, desfrutar de várias oportunidades e ofertas de mercado.

Dessa forma, as pessoas dispõem de uma grande variedade de produtos e serviços, o que altera seu comportamento de escolha, tornando-as mais exigentes. Consequentemente, as empresas precisam fazer melhorias significativas não apenas para competir e prosperar, mas para sobreviver, tornando-se vital saber o que os clientes desejam e pensam. Assim, o marketing tradicional tem dado lugar ao novo marketing, no qual as organizações devem enfatizar seus esforços nos clientes atuais visando conquistá-los.

Vavra (1993, p. 47) afirma que é fundamental, no marketing de relacionamento, o "reconhecimento da importância de tratar cada cliente individualmente e conduzir negócios de forma totalmente sob medida, não importando o tamanho da empresa". McKenna (1992, p.06) confirma a ideia defendendo que o marketing tem a função de "integrar o cliente à elaboração do produto e desenvolver um processo sistemático de integração que dará firmeza à relação".

Para Zeithaml e Bitner (2003, p. 113), o marketing transacional tem dado lugar ao marketing de relacionamento porque, "quando as empresas se concentram demasiadamente na atração de novos clientes, podem falhar quanto à compreensão das mudanças que ocorrem nas necessidades e expectativas dos clientes atuais". A busca das empresas por estabelecer relacionamentos duradouros tem sido uma 
tendência, vindo de encontro ao marketing de relacionamento, que enfatiza a construção e manutenção de relacionamento lucrativo com os clientes, oferecendoIhes maior valor e satisfação (KOTLER, 1998).

Portanto, Chauvel (2000, p. 11) afirma que "a satisfação do consumidor é, para as empresas, o único meio de conseguir obter e manter clientes. Constitui, portanto, um objetivo imprescindível para as organizações". Assim, pesquisas de satisfação tornam-se uma ferramenta valiosa na medida em que captam a opinião do cliente a partir da avaliação do desempenho da organização, alavancando melhorias ou identificando novas oportunidades, visto que clientes satisfeitos voltam a fazer negócios com as empresas.

O segmento de nutrição animal cresce a cada ano, tendo em vista que o Brasil é o terceiro maior produtor mundial de rações. O mercado aberto a novas empresas amplia a concorrência e oferece mais opções ao consumidor, sendo vital para as empresas brasileiras do setor investirem na retenção de seus clientes. Segundo o Sindicato Nacional da Indústria de Alimentação Animal - SINDIRAÇÕES, o setor sofre grande influência pelo comportamento de compra do consumidor e suas exigências em relação ao suprimento e à segurança dos alimentos (SINDIRAÇÕES, 2011). Assim, diferenciam-se as empresas que conseguem agregar valor a partir do atendimento focado nas necessidades dos clientes.

Considerando que o marketing de relacionamento é hoje um dos principais meios para a organização garantir a sua permanência competitiva no mercado, estudar o perfil do consumidor e os atributos que valoriza acerca do produto/serviço é fundamental para mantê-lo. Assim, as pesquisas de marketing constituem-se em um veículo central para conhecer a percepção dos clientes acerca das estratégias adotadas pela empresa.

Partindo da necessidade de analisar o conjunto de atributos mercadológicos definidos pela empresa visando à satisfação de seus clientes, bem como obter um maior conhecimento a respeito destes, de forma a atender a suas demandas e oferecer-Ihes um valor superior, surge o questionamento: as estratégias e práticas atualmente utilizadas pela fábrica de rações em estudo estão sendo efetivas para satisfazer seus clientes? Para tanto, o objetivo geral desta pesquisa foi analisar as principais estratégias utilizadas pela fábrica de rações em estudo para satisfazer seus clientes, utilizando-se, para isso, avaliação da percepção destes e do público interno (funcionários e gestor). 
O presente artigo se estabelece em quatro partes: inicialmente, apresenta-se a revisão bibliográfica sobre marketing, subdividido em composto de marketing e marketing de relacionamento; seqüencialmente, a metodologia, a análise dos resultados e, por fim as considerações finais do estudo.

\section{MARKETING}

Segundo Vavra (1993, p. 41), "marketing é o processo de conceber, produzir, fixar preço, promover e distribuir ideias, bens e serviços que satisfazem as necessidades de indivíduos e organizações". Kotler e Armstrong (1998) complementam esta definição ao afirmarem que o marketing, dentro de uma empresa, é a função que identifica as necessidades e os desejos do consumidor, determina quais os mercados-alvo a que a organização pode servir melhor, além de planejar produtos, serviços e programas adequados a esses mercados.

Segundo Silva e Tabosa (2014, p.4), "marketing pode ser entendido como um processo gerencial e social que visa atender e satisfazer os desejos e necessidades de um determinado público-alvo por meio de trocas de produtos e serviços que geram valor às partes envolvidas nesse processo". O marketing tem como foco principal as necessidades e os desejos das pessoas, sendo importante distinguir estes termos. Conforme Kotler e Armstrong (1998), necessidade é um estado de carência percebida, que não é criada pelas empresas, visto que representa uma parte básica da constituição do homem. Por sua vez, as necessidades são moldadas pela cultura e personalidade do indivíduo, criando os desejos.

Para Cobra (1992), seu papel é identificar as necessidades não satisfeitas do cliente, colocando no mercado produtos ou serviços que atinjam esse objetivo e, ao mesmo tempo, gerem lucro aos acionistas, além de ajudarem a melhorar a qualidade de vida das pessoas e da comunidade em geral.

Segundo Gordon (1998), o composto de marketing passa por transformações advindas do marketing de relacionamentos, sendo melhor explorados, na sequência, ambos os conceitos e suas conexões. 


\subsection{Composto de Marketing}

Para Madruga et al. (2011, p. 99), o composto ou mix de marketing representa a "combinação de ingredientes de que os profissionais de marketing se valem para atingir os objetivos de retorno". Kotler e Armstrong (1998) complementam esta definição descrevendo um mix de marketing, ou seja, as ações da empresa com intuito de manipular a demanda dos seus produtos, sendo dividido em quatro grupos, ou melhor, quatro Ps: produto, preço, praça e promoção. Segundo McCarthy e Perreault (1993), através dos 4Ps há muitas maneiras possíveis para satisfazer as necessidades dos clientes-alvo, considerando a seleção e combinação de variáveis, exercendo influência sobre os canais comerciais e os consumidores finais.

Sandhusen (1998, p. 273) afirma que "todos os elementos do composto de marketing derivam logicamente de como o produto e seu mercado são definidos". Compreender como os benefícios do produto satisfazem as necessidades do mercado-alvo, ajuda a determinar onde este produto deve ser distribuído ou como ele pode ser promovido mais eficazmente.

"Do ponto de vista do cliente, um produto é um pacote de elementos tangíveis e intangíveis que juntos oferecem valor para satisfazer seus desejos e necessidades" (NICKELS; WOOD, 1999, p. 7). Explicando desta forma como um produto pode auxiliar na construção de relacionamentos, considerando que quando ele oferece mais do que os elementos básicos e entrega valor superior ao cliente, acaba incentivando a sua lealdade, que por sua vez leva a relacionamentos mais fortes e duradouros. Madruga et al. (2011) ainda complementam esta visão ressaltando que um produto oferece benefícios e valores aos consumidores, como conforto, prestígio e segurança, contudo, isso não é suficiente para satisfazê-los, devendo a empresa focar no desenvolvimento de produtos que agreguem benefícios ao comprador com a oferta de sistemas, processos e serviços complementares.

A respeito do preço Nickels e Wood (1999) definem ser uma troca de marketing mutuamente benéfica, o cliente recebe o pacote de valor com todos os benefícios associados ao bem ou serviço, enquanto que o vendedor recebe o preço, que nada mais é que a quantidade de dinheiro ou algo mais de valor que solicita em troca do produto. Sandhusen (1998, p. 375) complementa que "preço é o valor de troca de um produto do ponto de vista tanto do comprador quanto da parte vendedora". "Em um sentido mais amplo, preço é a soma dos valores que os 
consumidores trocam pelo benefício de possuírem ou usarem um produto ou serviço". O preço é o único elemento do mix de marketing que produz receitas, considerando-o inclusive como o mais flexível do composto (KOTLER; ARMSTRONG, 1998, p. 235).

Referente ao composto de marketing praça, muitos autores se referem também como canal de marketing ou canal de distribuição, ao qual Sandhusen (1998, p. 335) atribuiu a seguinte definição: "todos os indivíduos ou organizações envolvidas no processo de movimentação dos produtos do produtor para o consumidor". Kotler e Armstrong (1998, p. 271) declaram que "as decisões referentes aos canais de distribuição são das mais importantes a serem tomadas pela empresa e afetam diretamente todas as outras decisões".

"Essas decisões são fortemente influenciadas pelo tipo de produto que está sendo comercializado, o ambiente competitivo no qual ele é comercializado, as políticas e recursos da empresa e as necessidades dos consumidores" (SANDHUSEN, 1998, p. 335). O autor também afirma que o ganho obtido ao saber tomar decisões corretas sobre o produto pode ser perdido se não forem dedicados cuidados iguais às questões de praça, de forma especial a respeito de onde o produto será oferecido e como fazê-lo chegar lá.

O quarto aspecto que compõe o mix de marketing refere-se à forma de promover os produtos. Na concepção de Sandhusen (1998), as pessoas precisam ser informadas sobre a existência de um produto ou serviço e convencidas de que este se trata da melhor opção. Kotler e Armstrong (1998) mencionam as ferramentas principais de um programa total de comunicação de marketing, sendo elas a propaganda, a promoção de vendas, as relações públicas e a venda pessoal, de forma que cada uma possui características e custos distintos.

Antunes e Rita (2008, p. 38) analisam as insuficiências do mix de marketing face à evolução das novas exigências da sociedade, afirmando que "este paradigma começou a ser fortemente criticado e começaram a aparecer diferentes alternativas aos 4Ps". Igualmente, Grönroos (2009, p. 241) considera esta necessidade de adicionar novas categorias às variáveis de marketing um sintoma de que essa abordagem fracassou, "uma lista nunca consegue incluir todos os elementos relevantes, não se ajusta a todas as situações e torna-se obsoleta".

Claro (2006) confirma que, no início do século XX, o marketing era essencialmente orientado para a produção. As empresas não se preocupavam com 
a venda, tudo que era produzido era comprado pelos clientes, independentemente dos atributos do produto ou das necessidades destes. No entanto, Saliby (1997, p. 6) faz uma consideração sobre a nova era competitiva: "o que é fundamental que os empresários compreendam é que os clientes estão se tornando cada vez mais exigentes e, diferentemente dos clientes de dez anos atrás, eles querem cada vez mais qualidade e menos preço". O autor justifica essa mudança destacando a crescente diversidade e quantidade de produtos e serviços ofertados, bem como a crescente concorrência global. Claro (2006) também concorda que mudança na abordagem do marketing está relacionada à competitividade, tanto em nível local quanto global.

De acordo com Grönroos (2009), no final da década de 70, surge uma abordagem alternativa, baseada no estabelecimento e gerenciamento de relacionamentos, elaborada através de duas correntes de pesquisa: a Escola Nórdica de Serviços, que partiu de uma perspectiva voltada aos serviços, e o marketing business-to-business, por meio de uma pesquisa do IMP (Internacional Marketing and Purchasing Group - Grupo Industrial de Marketing e Compras). Ainda segundo o autor, um ponto comum entre essas duas escolas de pensamento é a visão de que o marketing é mais uma questão relativa à forma de gestão do que, simplesmente, uma função empresarial, devendo ser construído sobre relacionamentos ao invés de transações (GRÖNROOS, 2009).

Dessa forma, o marketing mudou de uma ideia de market to, na qual os consumidores eram pesquisados para possibilitar a oferta de produtos que atendessem às suas necessidades", para market with, na qual consumidores são parceiros da empresa na co-criação de valor (PACHECO, 2017). De acordo com Antunes e Rita (2008, p. 38), o marketing de relacionamento "surge assim como a progressão de diferentes áreas substantivas para as respectivas teorias específicas que, posteriormente, através da experiência prática e do senso comum, dão origem à teoria geral do marketing relacional".

\subsection{Marketing de Relacionamento}

O marketing de relacionamento representa uma mudança de paradigma para a área de marketing, saindo de um foco em compras/transações para outro em retenção/relações. Para Zeithaml e Bitner (2003, p. 139), "é uma filosofia de fazer 
negócios, uma orientação estratégica cujo foco está na manutenção e no aperfeiçoamento dos atuais clientes, e não na conquista de novos clientes". Os autores ainda explicam o motivo de o jogo de marketing transacional dar lugar ao marketing de relacionamento: "quando as empresas se concentram demasiadamente na atração de novos clientes, podem falhar quanto à compreensão das mudanças que ocorrem nas necessidades e expectativas dos clientes atuais" (ZEITHAML; BITNER, 2003, p. 113).

Contudo, durante anos, os vendedores concentraram suas atenções na realização de novas trocas ao invés de desenvolverem relacionamentos mais estreitos com os clientes. A tabela 1 apresenta aspectos que demonstram essa diferença entre as abordagens de marketing.

Tabela 1 - Marketing transacional versus marketing de relacionamento

\begin{tabular}{|c|c|}
\hline Marketing Transacional & Marketing de Relacionamento \\
\hline 1. Ênfase em conquistar novos clientes & $\begin{array}{l}\text { 1. Ênfase em manter os clientes atuais, bem } \\
\text { como em conquistar novos }\end{array}$ \\
\hline 2. Orientação para o curto prazo & 2. Orientação para o longo prazo \\
\hline 3. Interesse em realizar uma única venda & $\begin{array}{l}\text { 3. Interesse em vendas múltiplas e } \\
\text { relacionamentos duradouros }\end{array}$ \\
\hline 4. Compromisso limitado com os clientes & 4. Alto nível de compromisso com os clientes \\
\hline $\begin{array}{l}\text { 5. Pesquisa sobre as necessidades dos } \\
\text { clientes utilizada para completar uma } \\
\text { transação }\end{array}$ & $\begin{array}{l}\text { 5. Pesquisa contínua a respeito das } \\
\text { necessidades dos clientes para melhorar o } \\
\text { relacionamento }\end{array}$ \\
\hline 6. Sucesso significa realizar uma venda & $\begin{array}{l}\text { 6. Sucesso significa lealdade do cliente, } \\
\text { compras repetidas, recomendações dos } \\
\text { clientes e baixa rotatividade de clientes }\end{array}$ \\
\hline $\begin{array}{l}\text { 7. Qualidade é uma preocupação da } \\
\text { produção }\end{array}$ & $\begin{array}{l}\text { 7. Qualidade é uma preocupação de todos os } \\
\text { empregados }\end{array}$ \\
\hline 8. Compromisso limitado com o serviço & 8. Alto grau de compromisso com o serviço \\
\hline
\end{tabular}

$$
\text { Fonte: Nickels e Wood (1999, p. 5). }
$$

Dessa forma, em contraste ao aspecto transacional, o marketing de relacionamento centra-se na construção de relações estáveis, ou seja, a empresa utiliza uma estratégia que focaliza a manutenção e a melhoria dos relacionamentos e, embora a obtenção de novos clientes seja ainda importante, o principal interesse estratégico é o de concentrar-se nos clientes existentes. Percebe-se que o novo 
conceito sugere que as empresas não devem fazer algo para o cliente, mas sim com e pelo cliente. Nesse sentido é que ocorreu a grande mudança em relação à estratégia de atuação em marketing, passando do marketing tradicional que continha uma visão de distribuição focada no produto, para uma visão de relacionamento com o foco no cliente.

De acordo com Saliby (1997, p. 7), "na abordagem do marketing de relacionamento, os clientes deixam de ser apenas números ou marketshare e passam a ser parte integrante da organização". Isso reforça o conceito de "trazer o cliente" para dentro da organização, de maneira que ele participe do desenvolvimento de novos produtos/serviços e crie vínculos com esta. Dessa forma, as empresas passam não só a ampliar seus mercados, mas também a procurar reter seus clientes e a atender a suas necessidades, tornando-se cada vez mais competitivas. A troca de marketing não acaba quando a transação é feita; na verdade, a relação entre vendedor e comprador pode tornar-se mais intensa depois da primeira transação.

Considerando a importância do marketing de relacionamento, torna-se necessário apresentar algumas concepções mais usuais, propostas por autores influentes, do que seja essa nova forma de conduzir os negócios em uma organização. Vavra (1993, p. 40) define o marketing de relacionamento como "o processo de proporcionar satisfação contínua e reforço aos indivíduos e organizações que são clientes atuais ou que já foram clientes". O autor declara, ainda, que manter clientes exige, das empresas, demonstração de cuidado e de interesse em relação a eles após a realização de uma compra.

Alguns autores também se reportam ao marketing de relacionamento como atividades de pós-marketing. "Frequentemente as empresas estão muito convencidas do desempenho de seu produto ou serviço, pressupondo que seus clientes experimentarão os benefícios de tê-lo comprado" (VAVRA, 1993, p. 38). No entanto, elas precisam conduzir seus clientes na descoberta da recompensa da escolha dos produtos ou serviços através de atividades de pós-marketing. Isso se justifica considerando que, atualmente, as pessoas buscam fazer negócios com empresas que ofereçam serviços agregados a seus produtos antes, durante e após a venda, a fim de que eles tenham a segurança de que suas necessidades serão atendidas, não somente hoje, mas também no futuro. 
Kotler e Armstrong (1998, p. 397) explicam o motivo desse enfoque em manter os clientes: "muitos mercados já atingiram a maturidade, e não há muitos novos clientes entrando na maioria das categorias. A competição é cada vez maior, e os custos para atrair novos clientes sobem cada vez mais". Afirmam ainda que, na busca das companhias pela participação em mercados esgotados, custa cinco vezes mais atrair um cliente novo do que manter um cliente antigo satisfeito. Claro (2006, p. 10) explica retenção como o "resultado de um conjunto de ações continuadas e monitoradas, nas quais os clientes percebem mais valor que o obtido em um relacionamento alternativo". Nickels e Wood (1999, p. 20) consideram também que "uma estratégia de marketing de relacionamento eficaz deve ser concebida para auxiliar na atração de novos clientes e para conseguir fazer mais negócios com os clientes atuais, maximizando, assim, o valor da vida útil deles”.

Segundo Vavra (1993), a importância da fidelização do cliente é reforçada pelo potencial destrutivo dos clientes insatisfeitos que deixam de realizar negócios com a empresa. A comunicação negativa que o cliente insatisfeito realizar pode prejudicar o desenvolvimento de novos negócios e a conquista de novos clientes. $\mathrm{Na}$ concepção de Claro (2006), a construção de relacionamento também está associada com a proximidade e a tentativa de entender e servir bem o cliente, além do que, requer confiança e outros elementos que dão suporte a ela, como o comprometimento, a comunicação e o entendimento. Com base nessa consideração, percebe-se que, para desenvolver o marketing de relacionamento, a empresa precisa, sobretudo, identificar seus clientes, aprender sobre eles e compreender suas necessidades e seus desejos.

Grönroos (2009, p. 34) lembra que "os clientes devem sentir continuamente que a outra parte está à disposição para ajudá-los e apoiá-los não apenas quando fazem uma compra". Ainda, o relacionamento é um processo contínuo e, mesmo os clientes realizando ou não trocas em um dado momento, a empresa deve tratá-los da melhor forma, pois, apesar de uma vez conquistado, o cliente não é fiel para sempre.

\section{METODOLOGIA}

Para atender ao objetivo proposto para o presente artigo, esta pesquisa é de natureza aplicada, tendo uma abordagem quantitativa e qualitativa. Quanto aos objetivos, é considerada descritiva, considerando que uma de suas características 
mais significativas, conforme Gil (2002), está na utilização de técnicas padronizadas de coleta de dados, sendo que os questionários elaborados para coletar as opiniões de clientes externos e internos inserem-se nessa classificação. Quanto aos procedimentos técnicos, trata-se de pesquisa bibliográfica, de campo e de levantamento (survey) aos clientes internos e externos.

Os sujeitos da pesquisa são 708 clientes ativos (conforme dados cadastrais), 41 funcionários e o gestor da fábrica. A amostra de clientes foi do tipo não probabilística por conveniência e contou com 150 clientes que vieram até a fábrica ou aceitaram responder à pesquisa por telefone. Também participaram 37 funcionários que atuam na área industrial, administrativa e de transporte, além do gestor da fábrica.

Utilizou-se, para a coleta de dados, questionário aplicado aos clientes internos e outro para clientes externos, ambos adaptados de Roesler (2014), com perguntas estruturadas e respostas fechadas com escala do tipo likert de cinco pontos, sendo que, ao final de cada questão, havia espaço para que o respondente se manifestasse de modo aberto. Também foram elaboradas questões que buscavam identificar o perfil dos respondentes.

Para o gestor, estruturou-se uma entrevista com 20 questões abertas, sendo a entrevista gravada e, posteriormente, transcrita. A coleta dos dados de todos os sujeitos da pesquisa ocorreu entre o período de 07/12/2015 a 29/01/2015.

Os dados coletados através dos questionários foram tabulados com o auxílio da ferramenta Microsoft Excel, recurso que permitiu o desenvolvimento de tabelas e apresentação de gráficos percentuais, possibilitando melhor visualização dos resultados da pesquisa.

\section{ANÁLISE DOS RESULTADOS}

\subsection{Caracterização Do Perfil Dos Respondentes Da Pesquisa}

Nesta etapa apresenta-se o perfil dos clientes e funcionários. Sobre o vínculo da amostra clientes, tem-se $83 \%$ associados da cooperativa e $17 \%$ que se constituem clientes terceiros. Além dos 708 clientes cadastrados, a fábrica relacionase com clientes terceiros, sendo compostos tanto por pessoas físicas quanto 
jurídicas. Portanto, é relevante ter estratégias adequadas para conhecer, bem atender e valorizar estes públicos.

Tabela 1 - Perfil da amostra

\begin{tabular}{|c|c|c|c|}
\hline \multicolumn{3}{|c|}{ Público interno } & Clientes \\
\hline Variáveis & Alternativas & Percentual (\%) & Percentual (\%) \\
\hline \multirow{4}{*}{$\begin{array}{l}\text { Idade } \\
\text { (anos) }\end{array}$} & Até 20 & 8 & 2 \\
\hline & De 21 a 30 & 22 & 9 \\
\hline & De 31 a 40 & 35 & 17 \\
\hline & Mais que 41 & 35 & 72 \\
\hline \multirow{2}{*}{ Gênero } & Feminino & 35 & 14 \\
\hline & Masculino & 65 & 86 \\
\hline \multirow{5}{*}{ Nível de Escolaridade } & Ensino Fundamental & 46 & 52 \\
\hline & Ensino Médio Incompleto & 16 & 8 \\
\hline & Ensino Médio Completo & 30 & 28 \\
\hline & Graduação Incompleta & 3 & 5 \\
\hline & Graduação Completa & 5 & 6 \\
\hline
\end{tabular}

Fonte: Autores (2017)

Dentre os 150 clientes que responderam à pesquisa, $86 \%$ são do gênero masculino, e 14\%, do gênero feminino. Em relação aos funcionários, também é expressivo o número de respondentes do gênero masculino, correspondendo a $65 \%$, enquanto que o gênero feminino corresponde a 35\%. Quanto à idade dos respondentes, em relação aos clientes, 72\% possuem mais de 41 anos, 17\% possuem de 31 a 40 anos, 9\% possuem de 21 a 30 anos e apenas $2 \%$ possuem até 20 anos de idade. Quanto ao quadro funcional, 35\% possuem mais de 41 anos, 35\% possuem de 21 a 30 anos, 22\% estão entre 31 a 40 anos, e $8 \%$ são os que possuem até 20 anos de idade.

Quanto à escolaridade, $52 \%$ dos clientes possuem ensino fundamental, $28 \%$ concluíram o ensino médio, $8 \%$ possuem ensino médio incompleto, $6 \%$ já possuem formação e os outros 5\% ainda estão cursando o ensino superior. Em se tratando dos funcionários, $46 \%$ possuem ensino fundamental, $30 \%$ concluíram o ensino médio, $16 \%$ possuem ensino médio incompleto, $5 \%$ já possuem formação em ensino superior, enquanto que $3 \%$ estão em fase de conclusão.

\subsection{Análise das percepções do público interno e externo}

Em relação ao primeiro fator analisado, clientes e funcionários deveriam mencionar quais os principais critérios utilizados na escolha da empresa para realizar suas compras. Dentre os motivos estão tradição e confiabilidade da 
cooperativa (31\%), qualidade dos produtos $(29 \%)$, atendimento e relacionamento $(13 \%)$, preço $(13 \%)$, variedade dos produtos $(9 \%)$, logística $(4 \%)$ e, ainda, foi citado como fator de escolha, a proximidade da empresa.

Já na visão dos funcionários, a qualidade dos produtos é o primeiro critério levado em consideração (36\%), seguido de tradição e confiabilidade (28\%). 13\% consideram atendimento e relacionamento; igualmente, $13 \%$ acreditam ser o preço o critério que atrai os consumidores, enquanto $6 \%$ mencionaram a variedade da linha de produtos, $3 \%$ referiram a indicação de outros clientes e $2 \%$ a logística adotada.

Com o intuito de identificar o que o consumidor considera relevante no cenário do mercado atual, foram questionados sobre quais as estratégias que melhor satisfazem o cliente. Na percepção dos clientes, a qualidade dos produtos é fator primordial para conquistá-los (28\%), seguido pelo atendimento (20\%). O preço representou $17 \%$ das opiniões, $14 \%$ afirmaram ser o conhecimento que a empresa possui e como ela valoriza seus clientes, $10 \%$ consideram importante o prazo para pagamentos, $8 \%$ valorizam a variedade de produtos que a fábrica oferece e $2 \%$ referem a influência do serviço logístico.

Quanto aos funcionários, $33 \%$ acreditam que os clientes se tornam satisfeitos pela qualidade dos produtos ofertados, $24 \%$ consideram a qualidade do atendimento, $19 \%$ consideram o conhecimento e a valorização dos consumidores, $3 \%$ destacam a influência do valor da marca, 14\% consideram que os clientes esperam por um bom preço, 3\% consideram importante a logística e 3\% valorizam a existência de condições de pagamentos como fator que satisfaz os clientes (Gráfico 1).

Gráfico 1 - Estratégias para a satisfação dos clientes

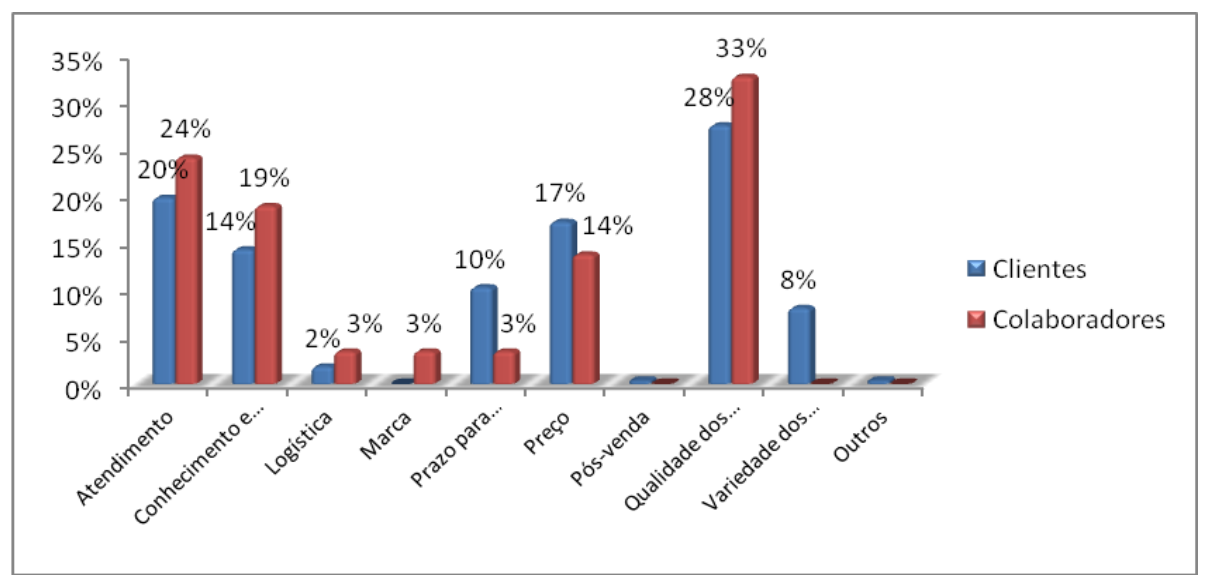

Fonte: Autores (2017) 
Quanto aos fatores que fazem com que os consumidores voltem a realizar suas compras na fábrica, os clientes responderam que voltam a negociar com a empresa pela qualidade das rações fabricadas (31\%), pelo atendimento prestado (15\%), pelo conhecimento e pela valorização (15\%), pela variedade de produtos $(11 \%)$, pelo preço praticado (15\%), pelo prazo para pagamentos (8\%), pela logística (4\%) e pela marca (1\%). No entanto, alguns clientes expuseram, no campo de opiniões, que repetem suas compras na fábrica por não haver outras empresas que comercializam rações no município.

Gráfico 2 - Fatores que influenciam a intenção de recompra

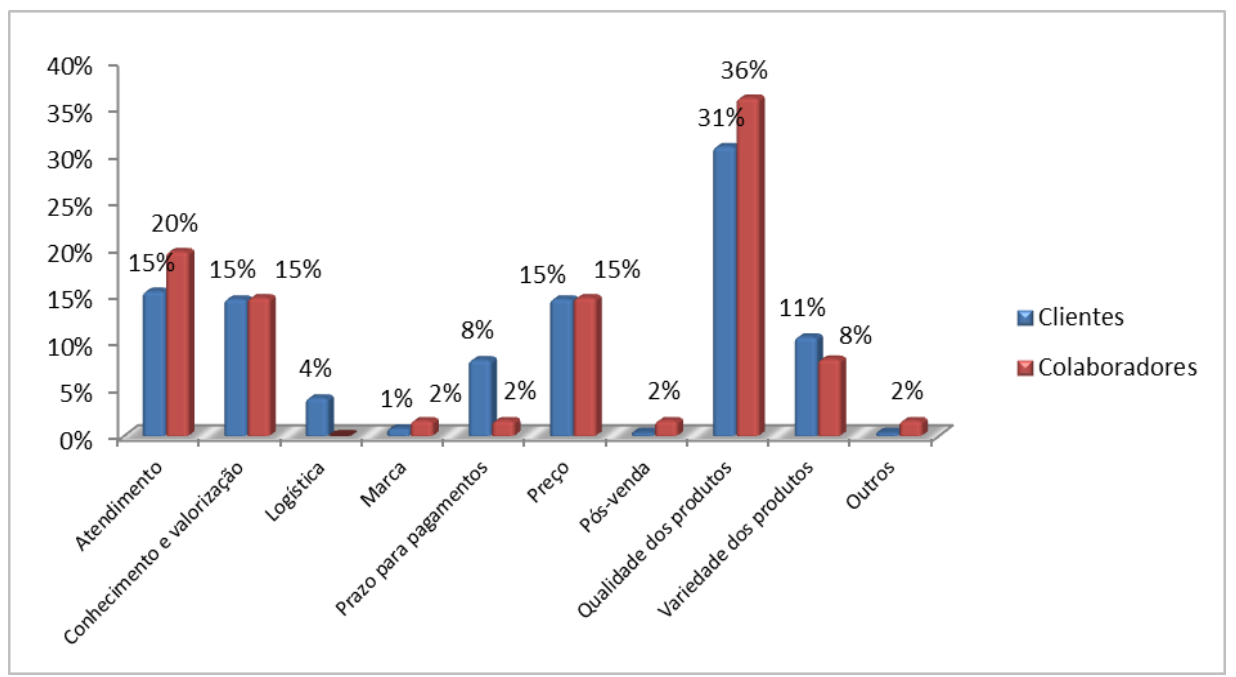

Fonte: Autores (2017)

$\mathrm{Na}$ visão dos funcionários (Gráfico 2), os clientes retornam pela qualidade assegurada dos produtos (36\%), pelo atendimento (20\%), pela compreensão e pelo reconhecimento da empresa em relação aos clientes (15\%), pelo preço dos produtos favorece $(15 \%)$, pela variedade de ofertas $(8 \%)$, pelo pós-venda $(2 \%)$, pelas condições de pagamento (2\%), pela marca $(2 \%)$ e pela confiabilidade da fábrica $(2 \%)$.

Em relação à satisfação dos clientes quanto à qualidade dos produtos fabricados, $77 \%$ encontram-se satisfeitos, $18 \%$, muito satisfeitos, $3 \%$, indiferentes e $2 \%$ consideram-se insatisfeitos. Em relação à opinião dos funcionários, $73 \%$ acreditam que os clientes estão satisfeitos, $19 \%$ julgam que estão muito satisfeitos, $5 \%$ acreditam que o produto não corresponde às expectativas, julgando-os muito insatisfeitos, e 3\% acreditam que os clientes estão indiferentes a este atributo.

Conforme entrevista realizada com o gestor da Fábrica de Rações, o setor desenvolve diversos tipos de rações e concentrados para nutrir bovinos, suínos, aves e peixes. O gestor afirmou utilizarem-se de estudos realizados sobre os 
ingredientes, sua eficácia e suas funções para garantir que as necessidades nutricionais do plantel de seus clientes sejam supridas. Sobre isso, alguns clientes expuseram, no campo de observações, que o composto das fórmulas pode ser aprimorado e enriquecido de mais vitaminas. Ainda de acordo com o gestor, seguindo as exigências do mercado, o Ministério da Agricultura, Pecuária e Abastecimento - MAPA, exige a implantação de Boas Práticas de Fabricação nos estabelecimentos produtores de alimentos para animais.

No que concerne à satisfação com a apresentação do produto (embalagem e rótulo), $75 \%$ dos clientes estão satisfeitos, $7 \%$ consideram-se muito satisfeitos, $12 \%$ estão indiferentes e $6 \%$ declararam-se insatisfeitos. Por sua vez, $76 \%$ dos funcionários acreditam que os clientes estão satisfeitos, $11 \%$ os consideram muito satisfeitos, $8 \%$ afirmam que estão indiferentes e $5 \%$ julgam que estão muito insatisfeitos com esse atributo do produto.

De acordo com o gestor, produtos de alimentação animal necessitam de proteção adequada, gerando grande responsabilidade para os fabricantes de rações. Para tanto, recomenda-se o uso de embalagens de material plástico, suficientemente seguras e resistentes para garantir a qualidade do produto, preservando as características das rações secas, bem como a conservação do alimento, protegendo-o contra as agressões de agentes externos.

Quando perguntados sobre a satisfação quanto à linha de produtos, $75 \%$ dos clientes consideram-se satisfeitos; $20 \%$, muito satisfeitos; $2 \%$, indiferentes; e $3 \%$ consideram que a fábrica deve melhorar a variedade de produtos. Com relação aos funcionários, $91 \%$ acreditam que os clientes estão satisfeitos e $5 \%$ julgam estarem muito insatisfeitos.

O gestor informou que a fábrica disponibiliza uma linha completa de rações para todas as fases e necessidades de diferentes tipos de animais. Sendo assim, não se pode eliminar nenhum produto, mesmo que sua procura seja baixa. Atualmente, o objetivo maior da linha de produtos é a rentabilidade do produtor, e por isso é que são oferecidos preços adequados e boa qualidade, buscando proporcionar o melhor aproveitamento. Com relação à diversidade dos produtos, a fábrica também disponibiliza a criação de fórmulas específicas e balanceadas de acordo com as necessidades de cada propriedade, porém este serviço personalizado direciona-se somente aos associados da cooperativa e não à 
totalidade de clientes, não podendo ser considerado como diferencial competitivo do setor.

A satisfação quanto ao atendimento, segundo a opinião dos clientes, apresenta um bom nível de satisfação, sendo que $78 \%$ encontram-se satisfeitos e $20 \%$, muito satisfeitos, enquanto que apenas $2 \%$ encontram-se insatisfeitos. Da mesma forma, $86 \%$ dos funcionários consideram os clientes satisfeitos, $11 \%$ acreditam que são indiferentes e 3\% julgam estarem muito insatisfeitos.

Para o gestor da fábrica, os clientes estão satisfeitos em parte com o atendimento proporcionado pelo setor. É fato que o pessoal do administrativo possui maior conhecimento e mais ferramentas para atender bem e de forma personalizada, porém, na área de transporte e entregas, em que há também contato com o público, reconhece-se a necessidade de investir em treinamentos aos funcionários.

Quando indagados sobre a satisfação quanto ao preço, $67 \%$ dos clientes dizem-se satisfeitos, porém 13\% consideram-se indiferentes e 15\% afirmam que estão insatisfeitos. $\mathrm{Na}$ visão dos funcionários, $68 \%$ consideram os clientes satisfeitos, $11 \%$ acreditam que estão indiferentes e $19 \%$ afirmam que os consumidores não concordam com a política de preços adotada.

Em se tratando das condições de pagamento oferecidas, os clientes, em geral, mostraram-se de acordo, pois $66 \%$ consideram-se satisfeitos, $19 \%$ muito satisfeitos e $11 \%$ manifestaram-se indiferentes. Com opinião semelhante encontramse os funcionários, dos quais $65 \%$ consideram os clientes satisfeitos, $8 \%$ acreditam que estão muito satisfeitos, $14 \%$ julgam serem indiferentes e $11 \%$ assinalaram que os consumidores estão insatisfeitos.

Outro aspecto avaliado por clientes e funcionários corresponde à logística adotada pelo setor. Observa-se que, entre os clientes, $70 \%$ consideram-se satisfeitos, $15 \%$ estão muito satisfeitos, $13 \%$ são indiferentes e $3 \%$ encontram-se insatisfeitos. Os funcionários, em sua maioria, também consideram que os consumidores possuem um alto nível de satisfação em relação à logística, sendo que $70 \%$ acreditam que estão satisfeitos, $11 \%$ julgam estarem muito satisfeitos, $14 \%$ opinaram que a fábrica não vem desenvolvendo um bom trabalho nesse quesito e $5 \%$ assinalaram que os clientes estão indiferentes.

De todos os critérios submetidos à avaliação, a realização do pós-venda pelo setor foi o que apresentou os maiores índices de indiferença por parte dos clientes, 
totalizando $35 \%$, o que ressalta a necessidade de empenhar esforços na concepção dessa estratégia, uma vez que a indiferença pode ser considerada negativa, sendo provável que o cliente não queira manifestar seu descontentamento. Os insatisfeitos com esse serviço representam $6 \% ; 51 \%$ estão satisfeitos e $9 \%$ estão muito satisfeitos. Os funcionários também reconhecem que tal aspecto tem apresentado lacunas, de forma que $27 \%$ consideram os clientes indiferentes, $8 \%$ consideram-nos insatisfeitos, $62 \%$ assinalaram que estão satisfeitos e $3 \%$ julgam estarem muito satisfeitos.

Outro quesito fundamental para a prática do marketing de relacionamento diz respeito ao conhecimento que a empresa dispõe sobre seus clientes, sendo que $72 \%$ dos clientes consideram-se satisfeitos, $17 \%$ declaram-se muito satisfeitos e $8 \%$ mostraram-se indiferentes. Dentre os funcionários, $84 \%$ acreditam que a fábrica sabe que produto oferecer por compreender a demanda e as exigências dos consumidores; $8 \%$ declaram que os clientes estão muito satisfeitos, porém $5 \%$ consideram que essa não seja uma estratégia de diferenciação para o setor.

Quanto à confiabilidade, $67 \%$ dos clientes demonstram-se satisfeitos e $29 \%$ apresentam um alto índice de confiança nos produtos e na gestão realizada pela fábrica. Do mesmo modo, $86 \%$ dos funcionários acreditam na boa reputação do setor perante os consumidores, $8 \%$ consideram-nos muito satisfeitos, porém $5 \%$ acreditam que os clientes estão muito insatisfeitos, sugerindo que a fábrica ofereça mais consistência em seu desempenho.

Conforme o gestor, busca-se assegurar a confiança e a credibilidade dos clientes através de uma oferta de qualidade e de uma postura ética, ou seja, garantir que o consumidor sempre receba aquilo que está sendo prometido. Assim, convém ao setor investigar, junto ao público externo e interno, os pontos falhos que levam a tal insatisfação, visto que o grau de confiança dos clientes em relação à empresa influencia diretamente no relacionamento estabelecido entre as partes.

Quanto à questão da valorização, $70 \%$ dos clientes consideram-se satisfeitos e $17 \%$ muito satisfeitos. Os funcionários também avaliaram o aspecto de forma positiva, considerando que $76 \%$ dos consumidores sentem-se valorizados e $16 \%$ estão muito satisfeitos. No entanto, não se descarta a possibilidade de a fábrica rever suas ações, pois o fato de os clientes apresentarem níveis de satisfação favoráveis em relação aos atributos elencados na pesquisa não significa que se 
sintam importantes para a empresa, uma vez que $13 \%$ mostraram-se imparciais à questão, podendo estes não estarem satisfeitos e optarem por não se manifestar.

Quando perguntados sobre a satisfação geral com a Fábrica de Rações, 75\% dos clientes afirmam que estão satisfeitos com a empresa e $23 \%$ afirmam estarem muito satisfeitos, sendo que apenas $2 \%$ consideram-se indiferentes sobre sua satisfação. Os funcionários, por sua vez, consideram um nível maior de satisfação dos clientes, totalizando $81 \%$ que os julgam satisfeitos e $23 \%$ que acreditam estarem muito satisfeitos, enquanto $3 \%$ dos respondentes consideram-nos muito insatisfeitos.

\subsection{Proposição de ações a partir da análise das potencialidades e fragilidades}

Através das opiniões de clientes e funcionários e das informações obtidas em entrevista realizada com o gestor da Fábrica de Rações, identificaram-se potencialidades e fragilidades quanto às estratégias adotadas pelo setor para satisfazer seus clientes, bem como em suas práticas utilizadas para estabelecer relacionamentos (Tabela 2).

Tabela 2 - Potencialidades e fragilidades quanto às estratégias utilizadas

\begin{tabular}{|l|l|}
\hline a) Qualidade dos produtos & a) Política de preços \\
b) Diversidade da linha de produtos & b) Condições de pagamento \\
c) Tradição e confiabilidade & c) Flexibilidade da logística (entregas) \\
d) Atendimento de qualidade & d) Capacidade de atendimento a demanda \\
e) Conhecimento sobre o cliente/uso de banco & e) Promoção dirigida exclusivamente aos \\
de dados & associados \\
f) Disponibilidade para implantar ou aprimorar & f) Serviços de pós-venda e assistência técnica \\
programas de relacionamento &
\end{tabular}

Fonte: Autores (2017)

A proposta do presente trabalho foi analisar o marketing de relacionamento, buscando reduzir a dispersão dos clientes a partir da fidelização dos mesmos, e, para tanto, fez-se necessária a mensuração das percepções dos clientes externos e internos em relação às estratégias da empresa. Os resultados obtidos possibilitaram entender que os clientes externos, de uma maneira geral, mostram-se satisfeitos com a fábrica de rações em estudo, pois reagiram de forma positiva em aspectos como qualidade do produto, atendimento, logística e confiabilidade, comprovando o que foi abordado tanto pelos funcionários como pela gerência. Todavia, como 
sugere a literatura consultada, esses fatores não garantem a fidelização do cliente, tampouco atribuem ao cliente uma total satisfação quanto ao produto ou serviço. Desse modo, recomenda-se que o setor revise alguns processos e desenvolva ações, tais como as sugeridas abaixo.

- Aprimorar o software de banco de dados: a existência de um sistema informatizado que possibilite maiores informações é muito relevante, uma vez que o banco de dados utilizado pelo setor funciona meramente como registro de emissão de notas fiscais e informações básicas sobre os clientes, e pelo fato de que se limita somente ao cadastro de seus associados. O sistema possibilitará o atendimento customizado, de acordo com as necessidades de cada cliente, bem como a geração de valor conjunto pelo registro de informações de suas preferências.

- Programa de pós-venda: para reter e fidelizar seus clientes, a empresa deve adotar um programa de pós-venda, visto que, conforme já resgatado na literatura, "manter os clientes exige que as empresas e organizações demonstrem cuidado e interesse por eles após terem feito uma compra" (Vavra, 1993, p.33). Assim, além da assistência técnica e do acompanhamento nas propriedades, sugere-se, ao setor, a formalização de uma área direcionada a reclamações de clientes e uma direcionada a suporte e garantias.

- Pontos de contato com os clientes: observou-se que a comunicação com os clientes acontece de forma casual e sem qualquer obrigatoriedade. Contudo, essa pode ser uma estratégia de baixo investimento e com resultados muito satisfatórios, pois entrar em contato com o cliente no momento certo possivelmente induz a uma nova compra e fortalece o relacionamento ao fazê-lo sentir-se valorizado e perceber a vantagem em assumir um compromisso com a empresa.

- Programas de comunicação: promover modificações no site institucional, visto que as informações sobre a fábrica de rações no site da cooperativa estão relacionadas ao segmento da indústria, limitando-se a uma breve descrição do que o setor oferece e a uma lista de produtos. É necessário expor, de modo organizado e técnico, o portfólio dos produtos, bem como manter a atualização dos dados. Além disso, os espaços, hoje existentes nessa seção, poderiam ser reformulados através de uma maior inserção de ferramentas de troca, ou seja, aproveitando-se as facilidades que a internet traz aos relacionamentos para estabelecer e manter as relações de comunicação, visto que essa geração online será a maioria da clientela, dos funcionários, dos associados, dos fornecedores e, até mesmo, dos gestores. 
- Programa para clientes perdidos: é relevante, para a empresa, acompanhar os níveis de recompra dos seus clientes, assim como observar quais deles desertaram, buscando as causas. Faz-se necessário funcionários designados a ouvir o consumidor, de modo a identificar o que o levou a deixar de frequentar a empresa, empenhando todos os esforços possíveis para recuperar clientes importantes. Portanto, a empresa precisa definir quais são os clientes que deseja reconquistar para que não haja desperdício de recursos na busca de clientes que não interessam mais.

- Avaliação da satisfação: tendo em vista o estabelecimento de barreiras para mudança de fornecedor e considerando que atributos diferenciadores (como o preço, por exemplo) podem ser facilmente copiados, sugere-se a mensuração da satisfação dos consumidores, de forma que a empresa possa analisar cada cliente, permitindo desenvolver seu conhecimento sobre cada um deles, seja para monitoramento de suas expectativas ou para avaliar sua satisfação pós-compra. Isso poderá ser feito de maneira informal, providenciando caixas de sugestões que estimulem a participação dos clientes, de modo a dar retorno às boas ideias ou atender às solicitações; ou através de pesquisas formais, semestrais ou anuais, considerando o entendimento de possíveis mudanças de comportamento dos consumidores.

\section{CONSIDERAÇÕES FINAIS}

A premissa de que o marketing vem aprimorando-se e acompanhando as mudanças e o desenvolvimento do mercado pode ser observada nas principais estratégias das empresas nas últimas décadas. Agora a abordagem do marketing passa a priorizar, de uma vez por todas, as relações, fortalecendo os vínculos e atribuindo aos clientes um valor inestimável.

Este estudo teve como objetivo avaliar se as estratégias e práticas atualmente utilizadas por uma Fábrica de Rações localizada no Noroeste do Estado do Rio Grande do Sul estão sendo efetivas para satisfazer seus clientes, para então serem propostas ações ou aprimoramento de procedimentos que contribuam para a construção de relacionamentos e, consequentemente, oferecer feedback sobre a opinião dos consumidores à gerência do setor da empresa em estudo. 
Portanto, foi possível identificar as percepções do público interno e externo, uma vez que foram levadas em consideração as opiniões de clientes, terceiros e associados, do gerente da fábrica e dos funcionários, de forma a integrá-las, buscando entender possíveis gaps e contribuindo para a proposição de novas estratégias. Tanto o público interno quanto o externo apontam qualidade oferecida, atendimento, conhecimento e valorização, bem como preço enquanto fatores que fazem o cliente retornar à empresa. Sendo perceptível que os clientes dão importância a esses critérios, é imprescindível que a empresa trabalhe para oferecêlos.

Os resultados demostraram que os clientes estão, de modo geral, satisfeitos com as estratégias da empresa no que tange à qualidade $(77 \%)$, apresentação e linha de produtos $(75 \%)$ e preço $(67 \%)$ dos produtos, sendo que a qualidade dos produtos é citada pela maioria dos clientes como fator de conquista (28\%) e como fator de recompra (31\%). Todos esses dados foram corroborados por dados semelhantes apurados junto ao público interno.

Em relação às percepções dos funcionários, estes consideram que os associados escolhem comprar na fábrica pelo fato de que preferem trabalhar com sua cooperativa, pela confiabilidade dos produtos, sendo que a preferência dos clientes terceiros justifica-se pela qualidade oferecida. Confrontando com a opinião do público externo, percebe-se que os critérios coincidem, pois ganharam ênfase a tradição e a confiabilidade das rações, bem como sua qualidade. Contudo, o mesmo reconhece que faltam estratégias que viabilizem a retenção de seus clientes, estabelecendo contatos frequentes e oferecendo mais vantagens, e que há viabilidade e suporte para que isso seja implantado.

A necessidade de manter os clientes deve levar a empresa a repensar suas estratégias de negócio, adotando programas que possibilitem um relacionamento duradouro. Assim, foi sugerido ao setor aprimorar o software de banco de dados existente, desenvolver um programa de pós-venda, estabelecer pontos de contato com os clientes, desenvolver programas de comunicação, adotar um procedimento para resgatar clientes perdidos, bem como realizar, de forma regular, avaliações de satisfação.

É importante, também, que a empresa reconheça que clientes fiéis constituem fonte de novas ideias e que cada relacionamento gera informações relevantes, sendo necessário que, muitas vezes, reveja a tecnologia e os processos utilizados, a 
fim de serem suficientemente flexíveis e adaptáveis. Não há um conjunto de ferramentas pronto para o marketing de relacionamento, pois este é, antes de tudo, uma filosofia em que se deve avaliar o que está sendo feito e reconhecer necessidades de mudar sistemas ou de desenvolvê-los para criar essa aliança.

Quanto às limitações da pesquisa, apesar de ser um estudo quantitativo, a generalização dos achados não pode ser estendida aos demais profissionais do estado, ou mesmo do Brasil, em função das diferenças e também da estrutura e cultura das organizações. Como sugestão de estudos futuros, indica-se a replicação desse estudo em outros contextos. Finalizando, este trabalho teve como objetivo primordial contribuir à área de pesquisa do campo do marketing de relacionamento, ampliando os conhecimentos sobre o mesmo.

\section{REFERÊNCIAS}

ANTUNES, Joaquim; RITA, Paulo. O marketing relacional como novo paradigma. Revista Portuguesa e Brasileira de gestão, 2008. 36-46 p.

BERRY, L. Emerging perspectives on services marketing. American Marketing Association, Chicago, p. 25-28, 1983.

CHAUVEL, Marie A. Consumidores insatisfeitos: uma oportunidade para as empresas. Rio de Janeiro, Mauad, 2000. 216 p.

CLARO, Danny P. Marketing de relacionamento: conceitos e desafios para o sucesso do negócio. São Paulo: Insper-IBMEC, 2006. 20 p.

COBRA, Marcos. Administração de marketing. 2. ed. São Paulo: Atlas, 1992. 806p.

GIL, Antônio C. Como elaborar projetos de pesquisa. 4. ed. São Paulo: Atlas, 2002. 175 p.

GORDON, lan. Marketing de relacionamento. São Paulo: Futura, 1998.

GRÖNROOS, C. Quo Vadis, Marketing? To w a $r$ d a Relationship Marketing Paradigm. Journal of Marketing Management, London, v. 10 p. 347-360. 1994.

GRÖNROOS, Christian. Marketing: gerenciamento e serviços. 3. ed. Rio de Janeiro: Elsevier, 2009. 424 p.

KOTLER, Philip; ARMSTRONG, Gary. Princípios de Marketing. 7. ed. Rio de Janeiro: Prentice-Hall do Brasil Ltda, 1998. 527 p.

LOPES, Francisca Flávia Plutarco; FREITAS, Ana Augusta Ferreira de; MOTA, Marcio de Oliveira. As Reações dos Consumidores diante das Falhas de Serviços a partir da Teoria da Atribuição. Revista de Ciências da Administração, Florianópolis, p. 37 - 50, abr. 2015. ISSN 2175-8077. Disponível em: 
<https://periodicos.ufsc.br/index.php/adm/article/view/2175-8077.2015v17n41p37>. Acesso em: 16 out. 2016.

McKENNA, Regis. Marketing de relacionamento: estratégias bem-sucedidas para a era do cliente. Rio de Janeiro: Campus, 1992.

MADRUGA, Roberto P. et al. Administração de marketing do mundo contemporâneo. 4. ed. Rio de Janeiro: Editora FGV, 2011. 148 p.

MALHOTRA, Naresh K. Pesquisa de marketing: uma orientação aplicada. 3. ed. Porto Alegre: Bookman, 2001. 719 p.

MCCARTHY, E. Jerome.; PERREAULT JR; William D. Basic marketing: a global-managerial approach. 11. ed. Boston: Irwin, 1993. 763 p.

MORGAN, R.; HUNT, S. The commitment-trust theory of relationship marketing. Journal of Marketing, Chicago, v. 58, July, p. 20-38, 1994.

NICKELS, William G; WOOD, Marian Burk. Marketing: relacionamentos, qualidade, valor. Rio de Janeiro: LTC, 1999. 498 p.

PACHECO, Natalia Araujo. Produzindo a Oferta com o Consumidor: Estratégias para Cocriação de Valor e Marketing de Relacionamento. Revista de Administração IMED, Passo Fundo, v. 6, n. 2, p. 251-261, mar. 2017.

ROBICHEAUX, R.; COLEMAN, J. The Structure of Marketing Channel Relationships. Journal of the Academy of Marketing Science, New York, v. 22, n.1, p. 38-51, 1995.

ROESLER, Gustavo M. Marketing de relacionamento: estudo das estratégias utilizadas para a satisfação dos clientes da empresa Autotintas Três Passos Ltda. Três Passos: 2014.

SALIBY, Paulo E. O marketing de relacionamento: o novo marketing da nova era competitiva. RAE-Revista de Administração de Empresas, 1997. 6-12 p.

SANDHUSEN, Richard L. Marketing básico. São Paulo: Saraiva, 1998. 494 p.

SILVA, Keina Maria Guedes da; TABOSA, Hamilton Rodrigues. Marketing de relacionamento em bibliotecas universitárias. Informação \& Informação, [S.I.], v. 19, n. 3, p. 219-241, abr. 2014.

SINDIRAÇÕES. Boletim informativo do setor. 2011. Disponível em: < http://sindiracoes.org.br/wp-content/uploads/2012/03/boletim-mar\%C3\%A7o-2011port.pdf>. Acesso em: 26 de Ago. de 2016.

VAVRA, Terry G. Marketing de relacionamento: como manter a fidelidade de clientes através do marketing de relacionamento. São Paulo: Atlas, 1993. 323 p.

VERGARA, Sylvia Constant. Projetos e relatórios de pesquisa em administração. São Paulo: Atlas, 1998. $90 \mathrm{p}$.

ZAMBERLAN, Luciano et al. Pesquisa em ciências sociais aplicadas. ljuí: Ed. Unijuí, 2014. $208 \mathrm{p}$.

ZEITHAML, Valarie A; BITNER, Mary Jo. Marketing de serviços: a empresa com foco no cliente. 2. ed. Porto Alegre: Bookman, 2003. 536 p. 